\title{
FRENTE AL PLAGIO: BUENAS PRÁCTICAS, ALEGRÍA Y ECOLOGÍA EN EL AULA
}

\section{AGAINST PLAGIARISM: GOOD PRACTICES, JOY AND ECOLOGICAL PEDAGOGY IN THE CLASSROOM}

\author{
Fernanda Llergo Bay \\ María del Pilar Alvear García
}

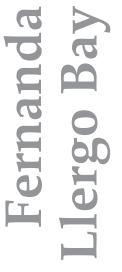

Doctorado en Filosofía y Letras, y Máster en Gobierno y Cultura de las Organizaciones, Universidad de Navarra, España. Maestría en Dirección y Gestión de la Innovación, Universidad Carlos III, Madrid, España. Licenciatura en Pedagogía, Universidad Panamericana, México. Líneas de investigación: tendencias de la educación superior, Antropología Filosófica, management, Filosofía Política.

fllergo@up.edu.mx

Maestría en Comunicación Organizacional, Universidad Panamericana, México. Especialidad en Periodismo, Universidad de Navarra, España. Licenciatura en Comunicación, Universidad Intercontinental, México. Ha sido docente de Comunicación Educativa, Normal Superior FEP, México. Líneas de investigación: Deontología Educativa, violencia, creatividad y comunicación. christa stahl@hotmail.com

\section{RESUMEN}

El auténtico estudiante y el auténtico maestro comparten el desafío de crecer para lograr una vida plenamente humana. En este sentido, es notable la representación del educador en la concepción náhuatl, 
resumida en la figura del sabio, aspiración última y siempre perfectible de quien busca educar para ir configurando en la persona, un rostro y un corazón.

El bien ser y hacer resultan del ejercicio perseverante y firme de la voluntad y la inteligencia, traducidos en la vivencia de buenas prácticas que exigen, desde luego — más que medidas anti plagio-, formación en honradez intelectual. El quehacer esencial del docente consiste en guiar al educando en la labor de descubrir y conservar un rostro y un corazón, en suma: la creación de una integridad personal que le permita protagonizar una vida digna, un quehacer ejemplar y una influencia positiva.

En la búsqueda por crear mejores modos de aprendizaje profundos y creativos en el ecosistema educativo que es el aula, un elemento puede resultar sorpresivo pero de ninguna manera sobrante: la alegría, nota indispensable del docente que ama lo que hace y lo transmite, encauzando al alumno en la ruta hacia el prestigio profesional y la felicidad personal.

Palabras clave: buenas prácticas, plagio, ecosistema educativo, alegría.

\section{ABSTRACT}

The true student and the true teacher share the challenge of growing to achieve an authentically human life. In this sense, the representation of the teacher in the Nahuatl conception is remarkable, summarised in the representation of the wise man, ultimate aspiration and always developing of whoever wishes to teach to configure, within the person, a face and a heart.

The well being and well-doing are the result of the persevering and firm exercise of the will and the intelligence, translated in the living of good practice that demand, of course - more than anti-plagiarism measures-, to develop intellectual honesty. The essential labor of an educator is to guide the student in the work of discovering and keeping 
a face and a heart: the building of personal integrity to perform a dignified life, exemplary work, and a positive influence.

In the quest to create better ways of learning that are deep and creative within the educational ecosystem that is the classroom, an element that can seem surprising but in no way excessive: the joy, indispensable note of the teacher that loves what they do and transmits it, placing the student on the path to professional prestige and personal happiness.

Keywords: good practice, plagiarism, educational ecosystem, joy.

Los agentes involucrados en la educación, docentes y estudiantes, buscan por igual algo en común: que su relato - personal, profesional y social - se envuelva en originalidad, creatividad y riqueza. En este sentido, la misión de quien educa es fundamental para ir desplegando alternativas, formas de percibir la realidad y su complejidad de maneras nuevas, propias.

\section{EDUCAR ROSTRO Y CORAZÓN}

El verdadero maestro busca encauzar al educando para lograr una existencia lo más íntegra posible; trascender el solo proceso de enseñanza-aprendizaje para prepararlo frente a retos, problemáticas y conflictos que le saldrán al paso a lo largo de la vida, y a los cuales deberá responder frente a sí mismo y frente a la sociedad.

Por ello, vale aludir aquí a la representación del educador en la concepción náhuatl que se resume en la figura del sabio, aspiración última y siempre perfectible de quien busca educar para ir configurando en la persona, un rostro y un corazón:

El sabio (tlamatini): «sabedor» es caracterizado como luz, guía, camino, depósito de la tradición, etcétera, pero ante todo llaman la atención las 
reiteradas alusiones al rostro: «[el sabio] enriquece los rostros ajenos, hace a otros tomar una cara, los hace desarrollarla [...], pone un espejo delante de los otros, hace que adquieran habilidades, los hace cuidadosos, hace que en ellos aparezca una cara». Lo que aquí se describe es la formación de la personalidad. [...] El espejo sirve en la medida en que hay un esbozo de rostro, para conocerlo, reconocerlo, actuar con conciencia de la propia identidad y así llevar ese rostro a su perfección.

En el texto sobre el sabio se menciona también el corazón: el sabio «conforta el corazón». Y ya que rostro y corazón constituyen la integridad de la persona, la obra del sabio en ella es una auténtica humanización: "gracias a él, la gente humaniza su querer y recibe una estricta enseñanza». ¿Qué más profundo que la voluntad? Por eso, la más radical humanización es la del querer (Jiménez Cataño, 1993: 70).

Es conveniente aspirar, pues, a ir cincelando en los otros - $\mathrm{y}$ en la misma medida, en uno mismo-, rostros y corazones, personas sensibles, honestas, esforzadas en querer su propio crecimiento y el de su entorno, involucrados así en la construcción de un mejor país y un mejor mundo. Esta concepción náhuatl sobre la educación, enlaza con los objetivos planteados por la UNESCO para 2030, orientados a una «educación de calidad integradora y equitativa, así como del aprendizaje a lo largo de toda la vida para todos» (Moran, 2019). La máxima sería tratar de humanizar el querer.

La concepción náhuatl evidencia la disonancia entre lo que la persona es per se y el modo en el que, de hecho, muchas veces la conceptualizamos para educarla. Se advierte la necesidad de actualizar la originaria vocación de educar, que los docentes se aboquen a sacar lo mejor de los otros y, al hacerlo, también de sí mismos. En ese tenor el plagio, por ejemplo, es antónimo de la honradez intelectual y, por lo tanto, del recto actuar, ese que busca ir configurando el propio rostro y el propio corazón, el que desea que el otro aprenda a narrar con veracidad — sin trapacerías-, descubriendo sus rasgos y su voz. 


\section{EL PLAGIO: «BONDADES»Y TRISTEZAS}

Según indica el Diccionario de la Real Academia de la Lengua Española, plagiar es «copiar en lo sustancial obras ajenas, dándolas como propias». Y el origen de la palabra plagio, también según la RAE, es el siguiente: "Proviene del latín tardío plagium "acción de robar esclavos", "acción de comprar o vender como esclavos a personas libres", y este

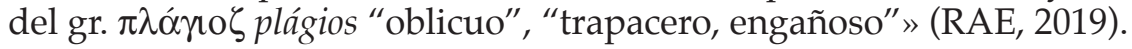

Es esta acepción del término la que resulta significativa: quien plagia, trafica; usa como propio lo que, de suyo, no le pertenece; se atribuye un mérito ajeno. Desde esta perspectiva de hurto, el concepto de plagio aparece como muy clarificador.

[...] en términos sencillos, podemos entender el plagio como la acción de apropiarse, mediante la copia textual, de una parte o del todo de una obra ajena sin dar el crédito correspondiente, y difundirla adjudicándose la autoría para obtener un beneficio particular, que puede ser desde reconocimiento y prestigio hasta retribución económica (Gantús, 2016: 12).

El plagio es miembro destacado de un universo más grande: el de la trampa. No es más que una concreción digital de la deshonestidad intelectual en la llamada era de la híper información. Y así, cuando existen -y existirán - cada vez más y mejores herramientas que regulen el correcto flujo de la información, también existen - y existirán- cada vez más sutiles formas de evadirlo.

Es primordial seguir trabajando en aspectos tecnológicos que reduzcan y disuadan del plagio, pero lo que es verdad al paso del tiempo es que, con o sin tecnología, no existe nada más libre y regulador que una conciencia que sepa dar razón de su actuar y sentido de rectitud a su quehacer.

No es habitual que alguien actúe de una manera incorrecta —en este caso, plagiando-, si no cree que ello le resulta en un beneficio. Conviene entonces analizar las «bondades» y/o justificaciones del acto del plagio. ¿Qué se «gana» al plagiar? Aunque seguramente existen muchas razones, estas son algunas que parecen saltar a la vista: 
1. En períodos intensos de estudios o tiempos laborales donde cada segundo cuenta, tener a mano información vasta y de fuentes fiables, permite y «garantiza» presentar trabajos de calidad en tiempo récord.

2. Alcanzar un determinado grado académico o estatus profesional.

3. En un universo de información ininterrumpida e infinita gracias a Internet, cada tema posee una inmensa cauda de información, por lo que el plagio aparentemente «ahorra» el esfuerzo de investigar.

4. Para académicos y/o instituciones, la presión por publicar, debido a los sistemas de promoción (contratos, prestigio, financiación...), puede resultar agobiante y el plagio, sutilmente disfrazado, es una opción que puede percibirse como válida.

5. Para los profesionistas es más fácil presentar un portafolio de trabajo y vestirlo con más material del que originariamente se ha elaborado.

6. No se sabe cómo citar adecuadamente y, por lo tanto, sencillamente no se cita.

7. No se tiene idea de que el no citar es, en realidad, robar las ideas de otros.

El plagio es plaga en aumento. Aunque esta mala práctica no se circunscribe en el mundo a latitudes o estratos sociales, cifras presentadas en 2018 por la empresa Turnitin indican, por ejemplo, que de 23 instituciones académicas de nivel medio y superior estudiadas en México, aproximadamente el 50\% de los trabajos allí presentados se hallaban bajo sospecha de plagio (Daniel, M., 2018).

Por otra parte, un estudio de los investigadores Reyes, Coronel et al. (2014) de la Universidad Autónoma Metropolitana, sirve para advertir y clarificar sobre algunas prácticas académicas nocivas entre universitarios. El cuestionario se aplicó a 180 voluntarios, con el objetivo de conocer las prácticas deshonestas entre ellos. Es importante 
señalar que el $56 \%$ afirmó no conocer la metodología adecuada para citar o referenciar, y el $22.5 \%$ indicó que en sus estudios de preparatoria nunca se les enseñó a hacerlo:

\begin{tabular}{|l|c|}
\hline \multicolumn{1}{|c|}{$\begin{array}{c}\text { PRÁCTICAS DE DESHONESTIDAD } \\
\text { ACADÉMICA }\end{array}$} & $\begin{array}{c}\text { PORCENTAJE DE } \\
\text { ESTUDIANTES QUE } \\
\text { HAN INCURRID0 }\end{array}$ \\
\hline $\begin{array}{l}\text { Presentar un trabajo previamente presentado } \\
\text { por él mismo. }\end{array}$ & 29.6 \\
\hline $\begin{array}{l}\text { Presentar un trabajo previamente presentado } \\
\text { por otro estudiante. }\end{array}$ & 31.8 \\
\hline Copiar texto de fuentes impresas y no citarlas. & 83.8 \\
\hline Copiar texto de páginas weby no citarlo. & 89.2 \\
\hline $\begin{array}{l}\text { Bajar un trabajo completo de Internet y } \\
\text { entregarlo como propio. }\end{array}$ & 34.3 \\
\hline
\end{tabular}

Fuente: Reyes, Coronel, et al., 2014.

Entre las consecuencias o «tristezas» del plagio, están:

a. A nivel personal, el plagio se va convirtiendo en un vicio, en una mala práctica que impacta en otras facetas, al promover el facilismo y el egoísmo.

b. Resulta intelectualmente empobrecedor para el individuo y la comunidad:

- Se replican contenidos sin análisis; no se aprende, no se innova, no se crea, no se relacionan ideas. Y sin ello, se pierden conceptos clave para el proceso de conocimiento personal, que devienen en herramientas indispensables y diferenciadoras frente a la Inteligencia Artificial (IA). 
- La persona se incapacita para parafrasear y asimilar referencias, e inhabilita su comprensión lectora.

- Se fomenta y normaliza el robo a la propiedad intelectual del autor original.

- La sociedad va generando entornos de menosprecio a la creación y originalidad que terminan retrayendo la oferta cultural.

c. Disminuye la confianza por presentar trabajos originales, a sabiendas que podrán fácilmente plagiarse.

d. Se obstaculiza la libre circulación de ideas, impidiendo que otros conozcan, discutan y / o profundicen sobre temas varios; el plagio genera infertilidad en el diálogo y, por tanto, estancamiento.

e. Si el plagio es grave, puede ameritar la expulsión de la carrera universitaria o de una institución académica, con la consiguiente difusión del mal comportamiento y el posible veto en otras instituciones.

f. Para el plagiario descubierto, cualquier trabajo académico pasado y posterior al plagio estará siempre en entredicho.

g. Aunque existen muchos vacíos legales, pueden tomarse acciones de represalia, multas o penalizaciones.

h. La institución académica donde el estudiante o miembro de la institución cometió el plagio puede ver afectado su prestigio; lo mismo que quienes han cursado sus estudios o han trabajado en esa institución.

Si la apropiación tiene lugar en un ámbito virtual, las fronteras son definitivamente borrosas a menos que exista una postura ética. Más que «atrapar» («cachar», decimos en México) alumnos, empleados o académicos que plagian, más que descalificar al que roba, la tarea de los docentes es educar, guiar, encauzar al otro en la labor de ir conformando rostros y corazones. Actuar rectamente importa, posee profundas consecuencias en lo personal y en lo social. 


\section{EL GATO Y EL RATÓN}

En reuniones de ex alumnos, una anécdota clásica gira en torno a cómo se evadió la norma, cómo se logró que el profesor no advirtiera un plagio, cómo se obtuvo una calificación genial no merecida, etcétera. Esta situación tan «normal» no tiene cabida si el encuentro es entre colegas docentes; ahí el asunto toma otro giro y el tema resulta inadmisible. ¿Por qué este salto radical? Es fácil señalar el problema y no advertir que, en ocasiones, se es parte de ese club de la trampa o, por lo menos, de la superficialidad. No es fácil percatarse que la incoherencia lastima la integridad y rasga íntimamente la conformación del tejido social. La congruencia es difícil, compleja, en este y en todos los sentidos. Si se desea contribuir a eliminar cada vez más las consecuencias negativas de un vivir poco ético, conviene actuar atinada y prácticamente para resolver lo que se ha cultivado o permitido que se cultive.

La deontología aplicada a la educación tiene [...] implicaciones que no pueden soslayarse. El educador no puede separar lo que es de lo que hace, y los criterios morales aplicados a la actividad educativa repercuten directamente sobre su personalidad, puesto que el ejemplo sigue siendo pieza fundamental en la tarea de educar.

El educador difícilmente podrá educar en valores que no comparta, de modo que dedicarse profesionalmente a educar supone un compromiso personal con un proyecto moral (Sarramona, 2002: 188-189).

¿Está bien jugar al gato y al ratón? ¿Al «tú engañas, te atrapo y te castigo»? Tal vez en algún momento el juego es necesario, pero sería triste, como docentes, quedarse inmóviles ante lo que debiera ser parte de una vocación fundamental: ayudar a comprender que el actuar correctamente es no solo bueno a la larga —en lo personal y en lo social-, sino que aprender con esfuerzo el arte de la rectitud en el actuar es labor apasionante y que consolidar una personalidad supone una mentalidad creativa, curiosa, libre y, por lo tanto, original.

Es esencial cambiar el juego: marcar diferencias en el quehacer cotidiano, en las aulas con pocos o muchos alumnos; animarles a actuar 
para lograr impactos positivos, buscando remediar esas carencias educativas. Es mucho lo que se juega al jugar al plagio.

\section{EL «ALAMBRITO», LA INVESTIGACIÓN Y EL APRENDIZAJE}

Es preciso contar con todas las herramientas anti plagio necesarias, pero ¿qué se hace para promover todas las herramientas pro honestidad? Un texto del catedrático Guillermo Porras Muñoz, miembro de número de la Academia Mexicana de Historia, titulado El alambrito: símbolo de la improvisación, analizaba cómo la creatividad del mexicano se resumía en el empleo que este hacía de un simple alambre, para resolver mil y una situaciones:

El recurso del alambrito hace destacar el ingenio del mexicano, que parece ser connatural a nuestros paisanos, así que no resulta del todo mal. En algo habíamos de destacar cuando nuestras condiciones de vida no permiten tener a la mano todas las herramientas que son menester para una compostura rápida y económica (Porras Muñoz, 1989: 9).

Este giro creativo que soluciona por vías impredecibles los problemas, no se circunscribe a los mexicanos; parece ser un modo en que razonan los latinoamericanos. Los mexicanos, chilenos, colombianos, etcétera, enriquecen la cultura del «meme» — que inunda las redes sociales- al generar permanentemente imágenes graciosas de esas vías o esos atajos con que se resuelven, creativamente, diversas problemáticas.

Porras Muñoz mencionaba en el citado escrito, tres graves consecuencias de la mentalidad del alambrito y que, coincidentemente, retratan la forma en que el alumnado generalmente prepara y presenta los trabajos «de investigación»: improvisación, flojedad en la voluntad y nulo deseo de superación. Ello se traduce en la ley del menor esfuerzo.

Parece válido proponer que esa forma de percibir y solucionar las distintas situaciones, esa capacidad de crear con lo que más a 
mano se tiene se vuelva una ventaja, previendo sus inconvenientes, y fomentando y apreciando sus beneficios: reorganización de conocimientos adquiridos; conexión novedosa de ideas de campos distintos; priorización de la creatividad sobre el enciclopedismo; promoción de la observación del fenómeno a tratar y cuestionamiento sobre el mismo, y análisis de la solución intuitiva para resolver un problema. Todo ello suma a un pensamiento reflexivo que se hace propio, formando hábitos de buena investigación y espacios adecuados de aprendizaje.

Un tema a tener muy en cuenta en este apartado es que, así como se desea que el alumno modifique su mentalidad por una donde él sea realmente protagonista principal de su formación y su narrativa vital, también el docente debe estar dispuesto a modificar la manera en la que presenta y califica el proceso enseñanza-aprendizaje: priorizar la originalidad y el esfuerzo que la creatividad conlleva, sobre una tarea by the book. Es lamentable que en ocasiones sea el maestro quien primero desilusione al alumno sobre lo que él piensa de sí mismo... cuando piensa por sí mismo. Sobrevive en muchos momentos la tendencia a calificar trabajos o exámenes meramente documentales o nemotécnicos, o simplemente solicitar tareas que completen determinado número de páginas, todo ello debido a la preocupación - entendible- del docente por concluir el programa de estudios, pudiendo propiciar así la simulación del verdadero proceso educativo.

Aunque es bien sabido que el complejo proceso de enseñanza-aprendizaje no depende, ni mucho menos, de la exclusiva actuación del profesor, sí es verdad que la impronta de este en su manera de impartir clase, su estilo docente, es un factor principalísimo en el ambiente que va conformándose en el aula.

Subrayado lo anterior $-\mathrm{y}$ conociendo que el docente no se enfrenta a problemas ni situaciones, sino a alumnos concretos (con sus intereses y características personales y socio familiares, sus formas peculiares de aprender, así como a sus conocimientos previos sobre la materia), a la organización de la escuela, al entorno... - , vale la pena apuntar lo señalado para ir afinando, cada vez más, una sensibilidad 
docente, activa y reflexiva, frente al conocimiento en sí y su forma de presentarlo y, sobre todo, de «entusiasmarlo» al discente.

A nivel de educación media y superior, no existe tradición de investigación en México: se enseña a presentar trabajos sobre los trabajos de otros, solo resumiendo lo que otros aportaron. Pero las diferencias entre un aprendizaje profundo y otro superficial (el cual hace referencia desde el fundamento psicológico en Pedagogía, a la teoría de Perkins [Jiménez y Torres, 2019]), pueden ofrecer parámetros para medir, reforzar o reestructurar el quehacer docente en el aula:

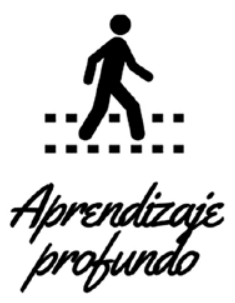

- Aprendizaje encaminado a la estimulación de operaciones mentales de mayor exigencia, que privilegien el relacionamiento, el vinculo y la teorización frente a la nemotecnia y la reproducción. - Incorporación reflexiva de nuevas ideas, integradas al conocimiento previo sobre el tema.

- Se favorece la comprensión y retención del saber, para integrarse a la solución de nuevas situaciones en contextos diferentes. - Resultan constitutivas actividades como el «análisis» (comparar, contrastar) y la «sintesis» (integrar el conocimiento en una nueva dimensión).

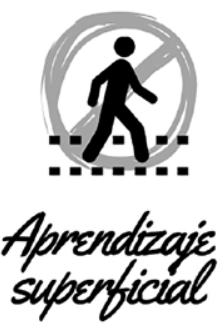

- Esfuerzo mínimo: el aprendizaje no transforma a la persona.

- Se memorizan hechos aislados, sin conexión con experiencias previas o con el contexto general.

- La información se enfoca a retener datos para aprobar, cumplir o elaborar una actividad.

- La habilidad cognitiva se orienta a «conocer». Ello explica el rápido olvido al poco tiempo de haber efectuado la evaluación.

Fuente: Jiménez y Torres, 2019. 
La profesionalización docente es asunto capital y es antónimo de la rutina y de la mera transmisión de información. Es indispensable repensar el modo de impartir clase y tomar decisiones que no solo involucren la forma de enseñar conocimientos, sino que cuestionen continuamente el papel del docente en el proceso educativo, priorizando y promoviendo el aprendizaje profundo, ese pensamiento singular — pensar «fuera de la caja»— que se le facilita naturalmente al alumno latinoamericano y que responde a un habitus investigativo: pensar críticamente, certeramente, reflexivamente para saber cómo emplear el «alambrito».

\section{ALEGRÍA, EL CORAZÓN DE UN BUEN APRENDIZAJE}

En este tenor de crear situaciones favorables que transiten hacia aprendizajes profundos y creativos, es decir, que sustenten mejores modos de aprendizaje, un elemento puede resultar sorpresivo pero, de ninguna manera, sobrante: la alegría. Señalaba Einstein una frase que apunta justamente a nuestro tema: «El arte supremo del maestro consiste en despertar el goce de la expresión creativa y del conocimiento» (citado en Calaprice, 2011).

El «entorno» de la investigación se conforma por cuatro capacidades transversales: reflexionar sobre la práctica; buscar y procesar información; vincular teoría y práctica; y conocer métodos y técnicas de investigación (cfr. Lozano y Echegaray, 2011). Pero la verdadera investigación no es solo eso; en ella, como corazón que palpita, subyace un sustrato de gozo. Pocas alegrías son más profundas que el entender intelectualmente algo. Ese entendimiento íntimo que conlleva la comprehensión se vuelca en un entendimiento experiencial: en una alegría.

Pero no es únicamente la alegría de la comprensión, la alegría es también el gozo - vocación primera- de quien enseña. La formación de hábitos y espacios adecuados de aprendizaje va muy de la mano de quien comparte, con entusiasmo alegre, lo que sabe. No se trata de tener docentes «chistosos», ni siquiera necesariamente simpáticos, pero sí de fomentar y traslucir la alegría de saber, de transmitir lo que se sabe y, sobre todo, de comunicar esa emoción por el conocimiento y, por lo tanto, por su investigación. 
Una de las acepciones de la alegría es aquella que proporciona el Diccionario de la Real Academia: «Avivar, hermosear, dar nuevo esplendor y más grato aspecto a las cosas» (RAE, 2019), y si se traslada al campo de la investigación, resulta en un concepto apasionante de lo que es la educación; el docente alegre será quien avive, hermosee, dé nuevo esplendor y más grato aspecto al saber. Algunas consecuencias que se desgranan de esta actitud, son:

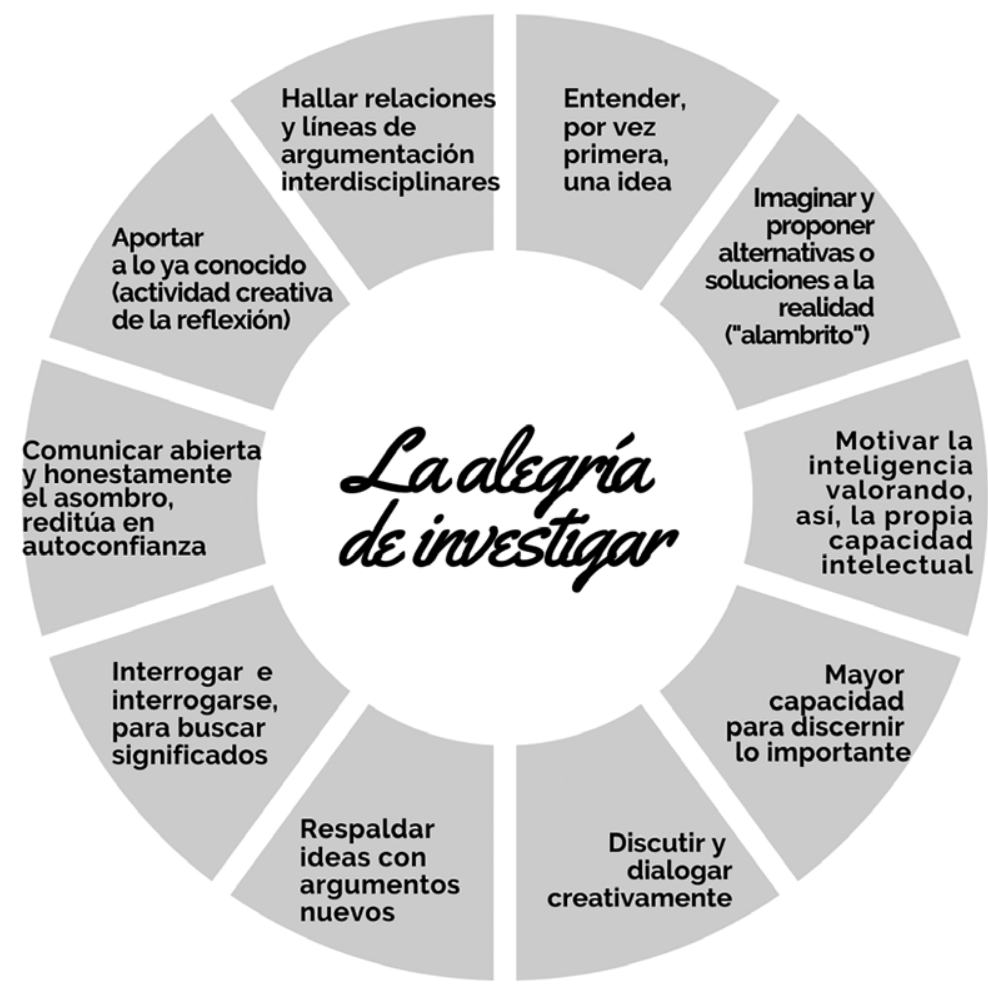

Fuente: Elaboración propia.

Es claro que el objetivo de cualquier quehacer docente es que el alumno aprenda, y una vía esencial para construir y reconstruir significados de una forma más profunda, supone un aprendizaje 
comprensivo, práctico, holístico. Cualquier persona recuerda maestros que, con su entusiasmo alegre por enseñar, por impulsar al estudiante a descubrir más — que en eso radica la investigación-, marcaron la manera de percibir una asignatura, por ejemplo. La vocación profesional de muchas personas se originó por un maestro que supo transmitir su ilusión por la materia que impartía; y el entusiasmo es una forma de alegría porque «inspira a...» (RAE, 2019). Lo que aporta un maestro apasionado a la construcción del conocimiento es incalculable, como incalculable es la trascendencia del conocer en un alumno.

La labor de educar no es fácil, ni cómoda, ni ágil, ni exenta de obstáculos, pero puede ser una aventura alegre, dependiendo de cada uno. Para algunos, educadores o educandos, la educación llega a ser un martirio. Para otros, puede ser una de las más afortunadas y fecundas experiencias. La alegría como la libertad, no consiste en no tener obstáculos o problemas, sino en saber superarlos.

[...] Nos consta también que, en su mayoría, los maestros están convencidos de la importancia de su labor, de la responsabilidad que entraña y del gozo grande cuando se preparan para ejercerla debida y oportunamente. La educación [es] una aventura ardua, demandante, pero positivamente fructuosa (Lerma Jasso, 2019: 117).

Aunque, en muchas ocasiones, quien educa esté enfrascado en necesarias habilidades mecánicas cotidianas y prácticas repetitivas, el afán debe ser el de comunicar a los alumnos la alegría de percibir el conocimiento con ojos nuevos; es decir, transformar el conocimiento en aprendizaje que trasciende. Ello reviste el papel del docente y ciertamente lo complejiza, trasladando su quehacer de la mera transmisión del conocimiento a la consecución de dirección, reflexión y autonomía en el discente. Pasar de una realidad objetiva a una realidad comprehendida y experimentada, descubierta alegremente, incide en profundidad en la manera como el alumno se apropia del conocimiento y de sus posibilidades de abrirse al mundo.

En el cuerpo, en la mentalidad, en la vida misma de quien educa, es donde se debe reconfigurar esa alegría que ayude a transformar el mundo. 
[...] Sin esto, deberemos insistir, el educador deja su enorme potencialidad para el cambio y se arrincona en el espacio de los que transmiten, de los que capacitan, de los que instruyen, pero no de aquellos hombres y mujeres llamados a contribuir al cambio en un mundo como el nuestro (Aldana, 2019).

\section{BUENAS PRÁCTICAS Y «ECOLOGÍA» DEL AULA}

Se apuntaba, haciendo referencia al concepto náhuatl del sabio, que la aspiración última del educador era cincelar rostros y corazones, personas avocadas conscientemente a su crecimiento y el de su entorno. «El maestro no es aquel que transmite un mensaje, sino que todo él es un mensaje», señala Carlos Cardona (citado en Lerma Jasso, 2019: 319).

Quien educa puede encontrarse inmerso en una cultura de la evaluación, pero es fundamental evaluar más allá de números referidos a respuestas concretas, más allá de un trabajo metodológicamente bien estructurado, más allá de contestaciones medianamente válidas, pues el objetivo radical es formar personas íntegras, ciudadanos que aporten con sus ideas, con sus acciones, con su voluntad a la construcción de mundos mejores.

Los números siempre confunden; se cree que el resultado total de un examen aprobado por todo el grupo es el éxito de una cátedra. No es así. La docencia es arte, trasciende los números porque, a veces, el número uno (un alumno que se ha percatado que puede cincelarse rostro y corazón) es, en realidad, todos los números. De hecho esas batallas modestas son, en realidad, las magnas batallas.

Así que además de contrarrestar trabajos académicos con herramientas anti plagio, ¿qué se hace en pro de la honestidad intelectual, pieza clave en la formación de la personalidad del discente y, por ende, del entorno donde él se desarrolla y desarrollará? A la pregunta qué se gana al plagiar, debe responderse con preguntas mayores y en positivo: ¿qué se gana cuando no existe plagio?, ¿en quién se va conformando el alumno al ser honesto? 
«La educación necesita profesores que transmitan emociones; que estén ilusionados con entregar un modo de vida a los estudiantes» (Nubiola, 2019) y ese modo de vida, incluye, como piedra fundamental, la honestidad intelectual y la alegría que conlleva.

No se lograrán buenas prácticas, si no existen hábitos buenos. Las primeras son, sencillamente, consecuencia de los segundos; por más que se desee dejar fuera el factor ético que permite la congruencia entre el buen pensar y el buen hacer, la persona está llamada, por naturaleza, a la unidad. No puede disociarse la idea de la acción, como su lógico resultante, so pena de volverse esquizofrénico. Razonar y actuar -mitades indisolubles - con congruencia, son pilares básicos de personalidades bien integradas. «La gran grieta de la cultura contemporánea se debe al hecho de haber separado, por una parte, el acopio de conocimientos, cada vez más abundantes, cada vez más profundos $\mathrm{y}$, por otra parte, la formación del carácter» (Llano, C., 1999). La Ética en la investigación, el buen comportamiento, el buen hacer tienen semilla en el buen pensar y el buen querer.

La labor docente no está exenta del desgaste. La forma de enseñar puede ser ya fruto de la fatiga frente a una sociedad que valora poco, en todos los aspectos, a la educación. Y va perdiéndose músculo para sostener la vida y van ganándose nervios para el desencanto y la apatía. Así que poco a poco, sutilmente, el quehacer docente puede volverse más «anti» y menos «pro». Es comprensible.

La docencia supone enseñar la trascendencia, personal y social, de la honestidad intelectual: a los alumnos se les prepara para el futuro, pero su futuro no será suyo si no están dispuestos a ser personas éticas. Indicaba Hanna Arendt:

[...] la educación, como la cultura toda, debe ser sometida a una reflexión profunda, a un examen más radical, capaz de revelar un humanismo nuevo que permita al hombre [...] comprender los lazos que, ineludiblemente, lo vinculan con todos sus semejantes y con la naturaleza toda, hallarse a sí mismo: humanismo que conduzca a un verdadero desarrollo integral que es: el desarrollo de todo hombre y de todos los hombres (citado en Lerma Jasso, 2019: 19). 
Llega, entonces, y eso es muy bueno, el momento de replantearse la vocación docente en busca - trabajo de investigación íntimo y doctoral- de aquella alegría primera. Es imprescindible hallarla, desempolvarla, vestirla con la ilusión del primer día de clases. El docente es -debe ser- su primer alumno: al ayudar a conformar personalidades, él mismo va cincelando la suya, en un ciclo orgánico, valioso y fecundo.

Alegría, profesionalidad, esfuerzo, asombro, generosidad, servicio. De ello debieran estar repletas las clases; eso debieran respirar los alumnos porque, no hay que olvidarlo, el esfuerzo educativo traspasa las aulas y la impronta - buena o mala- de un maestro puede transformar existencias. Tantas veces se empobrece la vocación docente a los límites de una cierta eficiencia estratégica para transmitir información, en pos de calificar aciertos y errores. $\mathrm{Y}$ eso es un esfuerzo muy pobre para dedicarle la vida.

Este quehacer busca tocar el rostro y el corazón de las personas... no solo de las que asisten a las aulas. No vale el tener miradas planas, esas que apenas logran ver muchos rostros frente a ellas; quien educa se relaciona con cada persona, aunque se dirija a todo el grupo; con el alumno que hoy está ahí sentado y mañana caminará trazando futuros para él y muchos otros.

La docencia presenta una cierta Ecología, según el modelo de enseñanza e investigación de Doyle y de Tikunoff:

Los modelos ecológico-contextuales estudian el aula como una realidad física y psicosocial en que se produce un complejo y dinámico entramado de variables que interactúan de formas diversas y que hacen de cada aula una realidad singular.

[...] sistema vivo donde sus elementos se definen en función del intercambio y donde el sistema va tomando forma a partir de la participación activa de todas las personas implicadas en los procesos de enseñanza-aprendizaje. Este clima de intercambios constantes son los que, a su vez, generan nuevos roles y patrones de actuación, tanto individuales como grupales (Domingo Roget, 2019: 28). 
Por ello, para no desperdiciar el potencial educativo del ecosistema particular que se despliega en cada clase, el docente debe cuestionarse qué subyace en la materia que imparte que pueda fascinar al alumno; qué clase de Ética le comunica al etiquetarlo como tramposo por haber plagiado, sin mostrarle la trascendencia de la honestidad en su propia vida - presente y futura - y del universo que se pierde al no protagonizar, creativa y originalmente, su trabajo... A ello debe apostarse al impartir clase, subrayando la trascendencia de la honestidad intelectual en la generación de círculos virtuosos; el plagio, la trampa, en cambio, los crean, pero en sentido inverso.

Esta Ecología del aula supone entusiasmar a los alumnos y a las comunidades, para pensar el quehacer educativo de otras maneras, sabiendo que descubrir, unir, interpretar es fundamental porque proporciona sentido, coherencia y unidad a la realidad que es siempre multidimensional, holística, asombrosa. No es posible renunciar al papel que exige tal misión: "Vale más proponerse la meta de la excelencia y no lograrla, que la de la mediocridad y conseguirla» (Llano, C., 1999). El docente debe esforzarse en narrar historias originales y creativas: las suyas, las de otros, gestando así —en rostros y corazones- revoluciones silenciosas.

\section{REFERENCIAS}

Aldana, Carlos (2019). «La llamada a la alegría en las aulas». El diario de la educación. Recuperado de https: / / eldiariodelaeducacion.com/ blog/2019/01/18/la-llamada-a-la-alegria-en-las-aulas/

Arendt, Hanna (1999). «De la historia a la acción». En Lerma Jasso, Héctor (2019). Hacia una pedagogía, de la alegría. México: Wissen \& Bildunc.

Calapatrice, Alice (2011). The Ultimate Quotable Einstein. Recuperado de https: / / press.princeton.edu/ titles / 9268.html 
Daniel, Mayra (2018). «Buscan disminuir el plagio académico». Revista Neo. Recuperado de https://www.revistaneo.com/articles / 2018/06/04/buscan-disminuir-el-plagio-academico

Domingo Roget, Àngels (2019). «La profesión docente desde una mirada sistémica». Revista Panamericana de Pedagogía. Saberes y quehaceres del pedagogo, 28 (julio-diciembre). México: Universidad Panamericana.

Gantús, Fausta (2016). «Conocimientos colectivos, obras particulares. Algunas reflexiones en torno al plagio académico». Perfiles educativos, XXXVIII(154), 12-19. Recuperado de http:/ / www.libros.unam.mx/ plagioyetica.pdf

Jiménez, Ana Lucía y Torres, Andrés Fernando (2019). «Las consignas escritas como instrumentos didácticos de aprendizaje y reflexión». Revista Panamericana de Pedagogía. Saberes y quehaceres del pedagogo, 28(julio-diciembre). México: Universidad Panamericana.

Jiménez Cataño, Rafael (1993). «La concepción náhuatl del hombre». Revista Istmo, 204(enero-febrero), 69-75.

Lerma Jasso, Héctor (2019). Hacia una pedagogía, de la alegría. México: Wissen \& Bildunc.

Lozano y Echegaray (2011). «Vacíos en la formación inicial de docentes en México. Programa para fomentar el habitus investigativo». En Mata Pérez, Ana Ma. et al. (2019). «Procesos de aprendizaje reflexivo en la investigación para la docencia». Revista Panamericana. Saberes y quehaceres del pedagogo, 28(julio-diciembre). México: Universidad Panamericana.

Llano Cifuentes, Carlos (1999). Viaje al centro del hombre. México: Diana.

Mata Pérez, Ana Ma. et al. (2019). «Procesos de aprendizaje reflexivo en la investigación para la docencia». Revista Panamericana. Saberes y quehaceres del pedagogo, 28(julio-diciembre). México: Universidad Panamericana.

Moran, M. (2019). Educación-Desarrollo Sostenible. Recuperado de https: / / www.un.org/sustainabledevelopment/es/education/ 
Nubiola, Jaime (2019). «La educación necesita profesores que transmitan emociones; que estén ilusionados con entregar un modo de vida a los estudiantes». Vida universitaria. Recuperado de https: / / www.unav. edu / web / vida-universitaria / detallenoticia6/2019/04/16/\%E2\%80\%9Cla-educacion-necesita-profesores-que-transmitan-emociones-que-esten-ilusionados-con-entregar-un-modo-de-vida-a-los-estudiantes\%E2\% 80\%9D / - / asset_publisher/w7Px / content/2019_04_15_fyl_noticia_alma_de_profesor/10174

Porras Muñoz, Guillermo (1989). «El alambrito: símbolo de la improvisación». Revista Istmo, 181(marzo-abril), 9-10.

Real Academia Española: Diccionario de la lengua española, 23 ${ }^{\mathrm{a}}$ ed. [versión 23.2 en línea]. <https:/ / dle.rae.es> [junio, 2019].

Reyes, Jorge Joel; Reyes-Méndez, Jorge; Coronel, Samuel y Flores, Rosalinda (2014). «Academic plagiarism from the perspective of students». Academia. Recuperado de https://www.academia.edu/24646278/ Academic_plagiarism_from_the_perspective_of_students

Sarramona, J. (2002). «La acción educativa». En Domingo Roget, Àngels (2019). «La profesión docente desde una mirada sistémica». Revista Panamericana de Pedagogía. Saberes y quehaceres del pedagogo, 28(juliodiciembre). México: Universidad Panamericana.

Yadel Chávez, Iris (2013). «Hombre y cosmovisión». Filosofía mexicana. Recuperado de https:/ / filosofiamexicana.org/2013/04/28/cosmovision-y-filosofia-nahuas / 